lowing ointment to rub along the under surface of the urethra three times a day :-

Extract of belladonna, a drachm;

Lard, half a drachm;

Mercurial ointment, two scruples;

Camphorated oil, sufficient to make into a soft ointment.

Also, a mixture of balsam of copaiba and solution of potash in equal parts, of which he is to take a small teaspoonful three times a day, in a cupful of infusion of linseed.

23. The symptoms of gonorrhœa are gradually sub. siding; the discharge is less and is more of a watery consistence; the hardness and soreness of the urethra have nearly disappeared; his bowels have not been moved for three days. To repeat the pill of calomel and extract of hyosciamus; to have a senna draught the following morning, and then to resume his mixture, but to substitute spirits of turpentine for the solution of potash. Continue the friction to the urethra, with the ointment.

30 . The only symptoms which remain of his disease are the following:-A slight discharge of muco-purulent matter, tenacious enough to glue together the lips of his urethra in the morning, which, upon pressing the urethra, are easily separated, and a large drop or two of yellow matter is forced out; during the day his shirt is slightly spotted; the edges of the external orifice of the urethra are redder than natural, but all the fulness has disappeared. He has abstained from spirituous liquors all through his treatment, but has taken a little porter at his dinner. To use the following injection four or five times a day:-

Alum, half a drachm;

Distilled water, ten ounces. Mix.

January 13. Dismissed cured.

He used no other medicines but the injection, except a dose of salts, which he prescribed for himself.

CASE III.-Jan. 27. Thos. - aged forty-one, applied here three weeks ago in the second stage of gonorrhœa. He stated that he had the discharge five days before he applied for relief; that it came on five days after connection; that it was unpreceded by any premonitory symptoms, but that scalding at the extremity of the penis supervened after the discharge had continued two days. He was ordered the copaiba mixture, with solution of potash, a drachm three times a day; this he took for a week, and it so alleviated all his symptoms that he gave up attending and went to his work, which was that of a stone mason.

He now complains of pain along the entire urethra, extending from the glans to the bulb; the urethra feels hard, like a cord, to the touch; the bulb is much swollen, and here he complains of most pain; when he coughs he fcels uneasiness in the perineum. He has had gonorrhœa three times, but not for the last five years; and from the appearance of his glans, a third of which is lost, he must have suffered also from syphilis. The dorsal vein of the penis was openea, but scarcely any blood could be obtained, on account of the small size of the vessel. Six leeches were applied to the perineum, and also fomentations during the day. He was ordered to take immediately an ounce and a half of castor oil, and after his bowels had been moved to take two tablespoonfuls of the following mixture three times a day :-
Camphor mixture, seven ounces;

Mucilage of gum arabic, three ounces;

Sweet spirits of nitre, five drachms;

Tincture of opium, a drachm and a half. Mix.

29. His symptoms are not much relieved. The discharge from the urethra has ceased altogether, and the swelling in the perineum is the size of a small hen's egg, is situated in the mesial line, is equally hard in every part, and has continued gradually to increase in size. He makes water with difficulty and with scalding both in the perineum and at the glans, but the size of the swelling is unaffected by the flow of urine. He was ordered to apply more leeches to the perineum, to encourage the bleeding by fomentations and poultices, and to take an aperient mixture.

February 11. This day the abscess was opened, and more than an ounce of purulent matter was discharged. Since last report he has had shivers, and on Sunday last he fainted. The abscess did not communicate with the urethra, and he makes water more freely than he did before it was opened.

21. The abscess has been healing from the bottom by granulation, and is now nearly closed; the bulb of the urethra is much diminished in size; the discharge has returned in a slight degree; he passes water as before, which continues to scald him at the bulb and glans.

This patient, Gentlemen, is still under treatment, and at our next meeting I shall make his case, as well as the others I have read, the subjects of illustration in speaking of the second stage of gonorrhœa.

\section{CASE OF CA TALEPS,} WITH REMARKS.

[Read before the Chichester Medical Society, Feb. 7, 1843.]

By George Miller, M.R.C.S.

(Published at the request of the Society.)

The case to which I would invite your attention on this occasion is that of the late Rev. J. G-, curate of $\mathbf{W}-$, who lived highly respected, and died at the age of thirty, deeply lamented for his talents and worth. The patient was tall, of stout, osseous frame, and had evidently been strongly muscular, of what I should call the sanguineo-nervous temperament, had always enjoyed robust health, and, until late, had been of florid complexion and cheerful disposition, although he was occasionally the subject of slight nervous depression. He was formerly intended for the bar, but, owing to his dislike of that profession, he subsequently entered the church, and became what will be well understood as a hard student. He had been ordained deacon to W-, to gain his twelvemonth's title for priest's orders. I mention these facts, trifling as they may seem, that you might have a thoroughly connected view of the whole case, and to show you that he still persisted in close application to his studies, in order to qualify him for his contemplated examination before the Bishop of Chichester, and that this intensity of sustained mental occupation was an immediate and exciting cause of the encephalic disease to which he afterwards fell a victim.

On the 21st of August, 1842, I was visited by Mrs. $O$., who requested me to call the next day on her nephew, the Rev. Mr. G-, at W-, as she en- 
tertained the most painful apprehensions not only as regarded his bodily health, but as to the state of his mind. On the 2'nd, however, about nine, a.m., I was sent for hastily to attend upon the reverend gentleman, in consequence, as the messenger alleged, "of the Rev. Mr. G__ having gone raving mad." I happened to be from home, but my partner, Mr. Spong, arrived there speedily, and the fact of insanity was soon established, for he was shown into a bedroom where the patient was kneeling in a state of complete nudity, dashing basins of cold water over himself, and praying most earnestly " that the waters of life he was now washing in would cleanse his soul from all sin."

Mr. Spong persuaded him to dress, and ultimately left him, more composed, under the care of his friends. On my return home in the afternoon, I saw him in consultation with Dr. M'Carogher, when it was made to appear, from himself and friends, that for some time previously the patient had betrayed much eccentricity in his habits and opinions, especially relating to religion, theoretically and practically, and that the particular event which brought on the crisis we then witnessed was shortly this:- $\mathrm{He}$ had that morning called on a notorious drunkard of the village to read him a sermon on his besetting sin, but his parishioner received his ministerial offices so contemptuously as to resolutely order the reverend curate out of his house. This conduct had such an effect upon his already excited feelings, that he rushed into the square of $\mathbf{W}$ - holding his Bible in the air, knelt down praying God to subdue the obduracy of the sinner's heart, and, rising up, began most vociferously to exhort people to repentance, for sin had darkened the land, and the judgments of God were coming upon the earth. After much difficulty he was compelled to go home, when he ran up into his bed-room, stripping himself, and washing as before stated. This process he had repeated thrice, and such was the intensity of his convictions respecting his own impurities, that each time he determinedly refused to be dressed in the same clothes, because they were un. clean; and even with us his anxious desire was to be again allowed to perform the same ablutions. We found him dressed, sitting in his study, and sullenly turning over the leaves of a Greek Testament, refusing all food and drink, exhibiting heartfelt distress at the sinfulness of man, beseeching us not to ask him any more questions, and, in fact, betraying himself in the most pitiable light of a religious monomaniac. We discovered that he had of late practised the most rigid religious discipline as regards fastings, tasting animal food only twice in the week, and often going to church on a Sunday morning without having broken his fast, and performing the entire duty. Another event which had contributed very materially towards his present condition was the miserable death of his brother, who was murdered by his own troops in the mele at Cabul, in India ; and this, conjoined with his rigid religious views and discipline, had deprived him of sleep at night, as well as considerably emaciated him for want of proper nutriment. He maintained that God could and would support him without any food if it pleased Him; nor could we succeed in showing him the fallacy of such an opinion, although we argued that God would not exert a miraculous power on his behalf, because he refused to avail himself of the good things of this life, which had been so bountifully placed within his reach. His head was rather hot, the conjunctiva a little vascular, and his pulse small and 76. His tongue was moist, and but slightly furred, and his bowels generally constipated. He declared himself free from all pain or sickness, and that he was quite well, excepting now and then a little headache. He was ordered to bed, to have leeches to the temples, cold lotions to the head, morphia in a small dose, with compound extract of colocynth; to be carefully watched, all religious books and water to be removed from his sight, and to have tea, coffee, or arrow-root, according to his choice. I saw him again at midnight; the leeches had bled freely, and I ordered him a blister to the nape of his neck.

August 23. No sleep; sullen and reserved, still dwelling upon religion; craving water to wash, and occasionally evincing symptoms of excitement; says he is in no pain, and refuses every kind of nourishment. He recognised a medical relative from London, who had come down to personally watch over and attend upon him. Head cool; pulse 78 ; bowels had not been acted upon, nor was it possible to give the pills; micturition free, and urine natural.

24. No variation, but that, during an interval of consciousness, he had taken the pills and an aperient mixture, which had operated freely. He seldom replies to questions, although he evidently understands them, saying, "Pray don't ask me; I am quite well, but you cannot judge of me." He has slept comfortably for two or three hours during the day, and has taken a little fruit and arrow-root. Head hotter, especially down the mesial line; tongue clammy; skin moderately warm; pulse 80 , and rather fuller. Ordered ice to be applied constantly to the shaven head.

25. Much the same this morning, and still imploring for water to wash, and pure water or pure wine to drink. In the middle of the day his looks became wild, and his actions evidently uncertain; indeed, from his anxiety to get the attendants to quit his room, no doubt he meditated self-injury. In the evening he seemed more composed and conscious, inquired after some absent relatives, and took a little bread and milk and fruit.

26. The quietness of last night was soon succeeded by restlessness and excitement, manœuvring to get his room vacated, and demanding hastily of the attendant, when he shut the window, whether he "was afraid of his getting out ?" He became so unmanageable now that it was deemed advisable to put him under corporeal restraint, confining or releasing him as circumstances justified. All this, however, subsided in an hour or two, and was followed by an attack of catalepsy, which still existed when I visited him at eleven, a.m. He was then lying motionless on his back; limbs straightened out; eyes half closed, injected, and suffused, and perpetually rolling; respiration 22 , and so tranquil as to be scarcely audible even close to the lips, but not unnatural in any other way save being a little abdominal; heart tumultuous in action, imparting a jerking sensation to the pulse, which was irregular as to frequency, varying constantly from 70 to 96 ; the head rapidly acquiring heat, if the ice was omitted for ever so short a period; 
profuse perspirations; feet and hands quite warm; tongue clammy and white; no epigastric or abdominal tenderness whatever; bowels inactive, and urine scanty, nor was the bladder in the least degree distended. On being raised in bed, the body remained fixed at any angle, and the head preserved any direction it was placed in; but this cataleptic action was far more marked in the upper extremities, which retained any position, however unnatural, fatiguing, and even impossible, for the same length of time under ordinary circumstances, although it required no force to effect any alteration, nor did the muscles themselves appear very prominent or hard. In the lower extremities the catalepsy was considerably modified as to its influence, but still prevailed to a certain extent. At three, p.m. (Dr. M'Carogher in consultation), his eyes were open, but fixed ; countenance looked conscious, and tolerably placid; there was occasionally slight strabismus, and yet the pupils acted beautifully, contracting upon the least light being thrown on the eye. He would not reply to any questions, and his teeth were so clenched that it was utterly impossible to administer anything through the mouth. Respiration 26, quiet and abdominal ; neither cardiac or respiratory auscultation elicited any abnormal sounds; indeed, the action of the heart was quite moderate, and the pulse, which had lost its "jerk," was 86 . Ordered leeches to the head; to persist in the ice application, and a blister between the scapulæ. Eight, p.m.: The patient continued motionless and unconscious all day, from three, a.m., till seven, p.m., an interval of sixteen hours, when he suddenly heaved a long and loud sigh, raised himself in bed, and inquired for wine. This being refused, he laid down again, soon relaping into his former state, but at midnight he again aroused, and partook calmly and freely of beef tea, arrow-root, bread, and a peach, the last of which he devoured so eagerly that he swallowed the stone, the peach having been most incautiously given to him whole by the attendant. At three, p.m., he again became unconscious, and was so at the morning visit of the

27. The leeches had bled freely; the respiration was now short and hurried; pulse 96 , and full; urine passed unconsciously, but no relief from the bowels; great heat along the mesial line of the head; eyeballs not painful on pressure; pupils act well, but the eyelids and lips have a perpetual quivering motion; the catalepsy fast disappearing, being only partial in the upper extremities. Ordered a pill, with croton oil. Eight, p.m.: The patient had now again been insensible for sixteen hours, and the liq. ammon. fort. applied to the nostrils had no other effect than the vapour causing his eyes to suffuse, and eyelids to wink when applied to the skin of the arm or abdomen; under a cupping-glass, he did not appear to know it, although it blistered the integuments at the epigastrium. Pupils continued obedient to moderate light; pulse, after changing his linen (during which operation he was perfectly helpless and insensible), rose to 104, but the moving did not alter his respiration, which had become audible; the saliva, however, flowed from his mouth whilst he was supported in the erect posture; urine still escapes involuntarily; gentle perspirations over the whole body, and the extremities comfortably warm. The croton oil not having operated, a turpentine enema was administered forthwith.

At eleven, p.m., I again saw him. He had been conscious for short intervals, resisting the removal of the strait waistcoat, saying "he was in fear of the Holy Ghost, and must keep it on." He was now again insensible, and the arms were strongly cataleptic, maintaining the most curious positions-pinching of the integuments, and the strong solution of ammonia when applied to the nostrils were disregarded. Pulse 100; carotids tranquil; respirations 26 ; tongue clean; discharge of urine involuntarily. The enema had not produced any evacuation of moment, so it was repeated, when it seemed to arouse him, exciting an hysterical effort to cry, and in about twenty minutes the injection brought away some scybalæ and grape husks, which had been swallowed, together with a quantity of healthy bilious dejection. He could not recognise any of his relatives, but he was uneasy at the church clock striking twelve.

28. Head and face hot and flushed, although the ice had been unremittingly applied; had slept occasionally for short periods; was insensible till raised in bed to change his linen, when he opened his eyes, took a few spoonfuls of beef tea, said he was in no pain, and again relapsed into his former state. The catalepsy of the upper limbs was more strongly marked in the evening than in the morning of this day. Injection repeated.

29. Throughout last night he continued much the same, the heat of the head having become excessive at the basilar region all round, but especially on the left side; the injection had fully evacuated the bowels; but at four, a.m., he was seized with violent convulsive gyrations, twisting him in a serpentine form from right to left, starting quite suddenly, and requiring the combined immense efforts of four men to confine him. When these convulsions ceased, he was still partially cataleptic in his arms; countenance indicated anxiety and pain; eyes sunken; head much cooler; pulse 104, but this and the action of the heart were evidently much weaker. He had, nevertheless, partaken freely of beef tea, and on one occasion asked for it. He had coughed several times, and expectorated a thick ropy mucus; great commotion in the bowels, and drawing up of the legs, as if griped. After one of the convulsions during the day, he aroused and said, "I am not long for this world."

30. More conscious to-day; replied coherently to several questions; said he had no pain in the head, but " that he should have by and by ;" asked to be washed all over in cold water, and had taken sufficiently of beef tea; had two convulsions during the night, and after each a little slecp, and this morning the catalepsy had disappeared; pulse 88; head cool; respiration natural; micturition involuntary; bowels had not acted. Ordered castor oil immediately.

31. Has been partially conscious at intervals since the last visit, and the gyrations had assumed a different character, drawing the head backwards, as in opisthotonos, and requiring great restraint, the whole body being strongly convulsed, without assuming any particular direction as before. The bowels had been copiously evacuated, but the urine still escaped without control; pulse 110, and feeble; tongue has as- 
sumed a dry, dark brown coat; eyes much sunken; respiration 18, and abdominal; pupils still act well, and the skin is bedewed with perspiration; head cool; extremities warm. Had taken beef tea and a little wine and water.

I will not detain you longer than by remarking that, from this time, he had occasional lucid intervals, answering questions easily and rationally, and that the catalepsy had completely vanished, although he had a convulsion occasionally. On the day of his death (Sept. 2) he had slept soundly and been comfortably washed and changed; he was perfectly sensible for several hours, inquiring for and conversing with his relatives, when suddenly he begged them " to throw him out of window, or give him a razor to cut his throat, for the man with the spectacles on (one of the watchers) was endeavouring to read his thoughts." Even at this time he was rapidly sinking; his pulse scarcely perceptible, but the heart beat 160 ; copious transudations upon the face; tongue dark brown; sordes on the teeth, and extremities cold. He still refused all food and nourishment, assuring his friends he was not so ill as the doctors imagined, and he should yet recover. He was persuaded to drink a little wine, shortly after which he became quiet, and calmly expired at six, p.m.

\section{Post-mortem.}

After some little difficulty I succeeded in obtaining a post-mortem examination of the head only, sixteen hours after death. The body was excessively emaciated, indeed it was a mere frame of bones, and the countenance strongly betrayed internal wretchedness. The scalp was very tough, and the bones of the head exceedingly hard; the vessels of the dura mater were turgid with blood, looking blue and prominent, and so adherent was this membrane to the cranium that it was impossible to separate it entire; the sinuses were loaded with blood; the arachnoid membrane was firm and opaque, having a fluid yellow fibrinous secretion between it and the pia mater-this was particularly manifest over the convolutions along the mesial line of each hemisphere, and on the left especially; pia mater gorged with blood; substance of the brain throughout unusually firm, and with dotted points of various sizes and dark colored; ventricles contained about one ounce and a half of transparent serum; base of the brain and cerebellum highly congested; the medulla oblongata was hard and tough, requiring considerable force to break it down between the fingers, but it was devoid of dotted points.

\section{REMARKS.}

On reviewing this case there can, I think, be no doubt that the cerebral disease was of slow and insidious growth, produced most probably in conjunction with predisposing causes by his severe mental discipline and his utter neglect of the physical necessities of the frame, as regards food, cheerful recreation, and exercise of mind and body. The character of the insanity is, I believe, sufficiently well accounted for by the nature of his studies-religion and the serious responsibilities of his professional situatich-and I am free to confess that the portions of brain to which phrenologists ascribe the functions of veneration were precisely the seat of the greatest vascular excitement, the most decided opacity and firmness of the arach. noid coat, and the most effusion between that mem. brane and the pia mater-a most striking evidence of deranged function in connection with organic disease. We are justified, too, in my opinion, in pronouncing the catalepsy a symptom supervening upon mania, inasmuch as the former appeared and ceased whilst the latter was steadily running its course; we must remember, too, that the catalepsy was not extaticthat is, not that abstracted and intense contemplative excitement, or that rigid, statue-like muscular action requiring immense force to move the limbs or trunk from any given positions, but simply muscular action without volition as ordinarily exercised. Again, it may be that the asthenic state of his physical frame, induced as it was by severe study and scanty nourish ment, might have so debilitated his nervous system as to modify the intensity of the cataleptic seizures, although it controlled not the violence of his convulsions, the one being continuous for days, more or less, the other sudden, powerful, but temporary. Another remark I would make is, that, although in this melancholy case the catalepsy was conjoined with a certain amount of hysteria, yet it more especially formed a part of the religious insanity, and hence the question arises, To what particular lesion within the cranium are we to attribute the supervention of the catalepsy? Will the induration of the brain and medulla explain this phenomena? Or, supposing the medulla spinalis throughout to partake of the same disease as the medulla oblongata, will that satisfactorily account for them ? Again, I have not been able to satisfy myself but that during (to us) his unconscious state, and as far as external influences were concerned, he was utterly lost, yet from the rolling of the eyes, the motion of the lips, with occasionally indistinct utterance and apparent momentary recognition of a sudden question, I feel assured that his mental faculties were engaged upon the subject matters of his maniacal delusions. It appears singular to me, also, that with such excessive disease about the brain, the poor patient should have been visited with so many lucid intervals, during which he would be so rational and his general symptoms be so subdued that we were almost inclined to hope for the best; and this state of things continued uj to the very day of his death, although the state of the encephalon, as developed after his decease, would have justified us in pronouncing raving delirium or complete insensibility. The disease of catalepsy, whether idiopathic or symptomatic, seems so rare and little understood that it would be useless to theorise more on the subject; but I will just summarily relate the treatment adopted.

It consisted of cold lotions and solid ice applied to the shaven head; relays of leeches to the temples and behind the ears, according to circumstances; blisters to the nape of the neck and between the scapulæ; stimulating liniments to the entire spine; calomel and opium to affect the mouth, but which, although administered in small and repeated doses whenever practicable, failed to induce the desired effect; aperients, turpentine enemas, and, lastly, when the tongue became dry and brown, and symptoms of exhaustion manifested themselves, wine and ammonia. Whenever, too, any great length of time elapsed without food, and he persisted in refusing it, good beef tea was thrown up the rectum. The only suggestion in addition to the above I would make is-whether a cold 
water douche over the body occasionally would be th admissible, although I hope never again to encounter so formidablc and pitiable a form of cerebral affection.

\section{ON CYNANCHE LARYNGEA.}

By Jonathan Toogood, Esq.,

Senior Surgeon to the Bridgwater Infirmary.

Cynanche laryngea sometimes is ushered in by an attack of common sore throat, and sometimes the two diseases are coexistent. Mrs. Burt, aged sixty-four, was seized with shivering, after exposure to cold, on Saturday morning, followed by fever and sore throat. The uvula and both tonsils were much inflamed and ulcerated; and in this state she continued to suffer much inconvenience until the following Wednesday morning, when she was so much relieved as not to require further attention. Her son being under $\mathrm{my}$ care at the time, I saw her at ten o'clock the same evening, when she declared herself free from all complaint, and told me that she had been sitting up at work the greater part of the day, and at that moment was preparing to assist in taking her son out of bed and making it for the night. On visiting him the following morning I was alarmed by hearing his mother, who slept in an adjoining room, breathing in a slow' laborious manner, with a shrill or stridulous sound. I found that she had been attacked with cynanche laryngea early in the morning, and was suffering from pain, cough, fever, and sense of suffocation. General and local bleeding, with large and repeated doses of emetic tartar and afterwards of calomel, together with counter irritation, were immediately resorted to-indeed all the usual remedies were actively and most energetically employed for ten hours, when she died quite suddenly. The remedies produced languor and faintness, but no effectual relief, although a partial abatement of the most violent symptoms lulled me into a false security, and prevented me from adopting that course which, I believe, would have saved her life. Never did I more sincerely regret that the operation of bronchotomy was not performed; but the duration of the disease was so short that I did not feel myself justified in proposing it until some means had been tried. It terminated in a more sudden and unexpected manner than I was prepared for. The dissection proved that the discase was confined to the upper part of the tube, which was blocked up by flakes of coagulable lymph; and as the surrounding parts were all in a healthy state, there is every reason to believe that the operation would have beeri attended with complete success.

Although the operation did not succeed in the case which I am about to relate, it will be found an interesting one-the patient, after a partial restoration, having died of secondary asphyxia.

Mr. Honitall, aged fifty, had been suffering for some days from what was considered a bad cold, attended with hoarseness and sore throat, for which some domestic remedies were used. He became much worse about ten o'clock at night, when he sent for a surgeon, who bled him largely both generally and locally, and treated him very actively during the night without any relief of the symptoms. I saw him at five on the following morning, and advised the immediate performance of tracheotomy, which he refused to submit to, but, rapidly getting worse, and gasping for life, he consented when in articulo mortis. But before the operation was completed he had ceased to breathe; it was persevered in, and artificial respiration performed, when, after a few minutes, to the great surprise of all around him as well as to myself, reanimation took place, he began to breathe freely, opened his eyes, sat up in the bed, and drank some tea. He continued in this state but a short time, was seized with conrulsions, and expired.

If, in this dangcrous disease, large bleedings and active remedies do not succeed within a few hours after its invasion, 1 believe the best course is to resort immediately to the operation, and not to wait until the powers of life are so far exhausted as to leave but little hope of success.

Bridgwater, Feb. 24, 1843.

\section{IMPERFORATE VAGINA.}

TO THE EDITORS OF THE PROVINCIAL MEDICAL. JOURNAL.

Genthenes,-Should you deem the following case of imperforate vagina of sufficient interest, you will oblige me by its insertion in your Journal.

I am, Gentlemen,

Your obedient Servant, Thomas Baxcks, M.R.C.S.

Stourbridge, Feb. 27, 1843.

In the month of April, 1842, Mrs. W-, aged twenty-eight, of masculine make, but well developed mammæ, who had never menstruated, applied to me for advice. She stated she was in good health, had been marricd five months, but that no entrance had been effected by her husband. On examining the external organs of gencration, I found a complete closure of the vagina, there being no opening but the orifice of the urethra, which was much dilated (and readily admitted ny finger into the bladder) by repeated attempts on the part of the husband to force an entrance with the finger. I at first thought the integuments only might possibly be the obstruction, and suggested to her the necessity of an operation, which she readily assented to; indeed, she stated her willingness to undergo any operation that would afford a chance of relief. Having evacuated the rectum and bladder, I commenced an incision immediately below the orifice of the urethra, and carried it on for three inches towards the anus, avoiding the urethra by keeping a catheter up against the pubis, and, carefully dissecting as I approached the rectum; I continued my incision inwards and upwards for about two inches and a half, until I found the rectum and urethra so closely approximated that I deemed it advisable to desist, having fully satisfied myself there was an entire absence of the canal of the vagina and, I believe, of the uterus also, as it could not be felt either through the rectum or bladder. The woman had never menstruated, or had any bad symptoms when that secretion should have taken place, and the bones of the pelvis, particularly the inferior outlet, had all the characteristics of the male pelvis; one artery only was divided and secured, the 